\title{
Desafios do desenvolvimento em Miracema (RJ): uma abordagem territorial sustentável de saúde e ambiente
}

Development challenges in Miracema (RJ, Brasil): a territorial approach for the sustainable management of health and environment

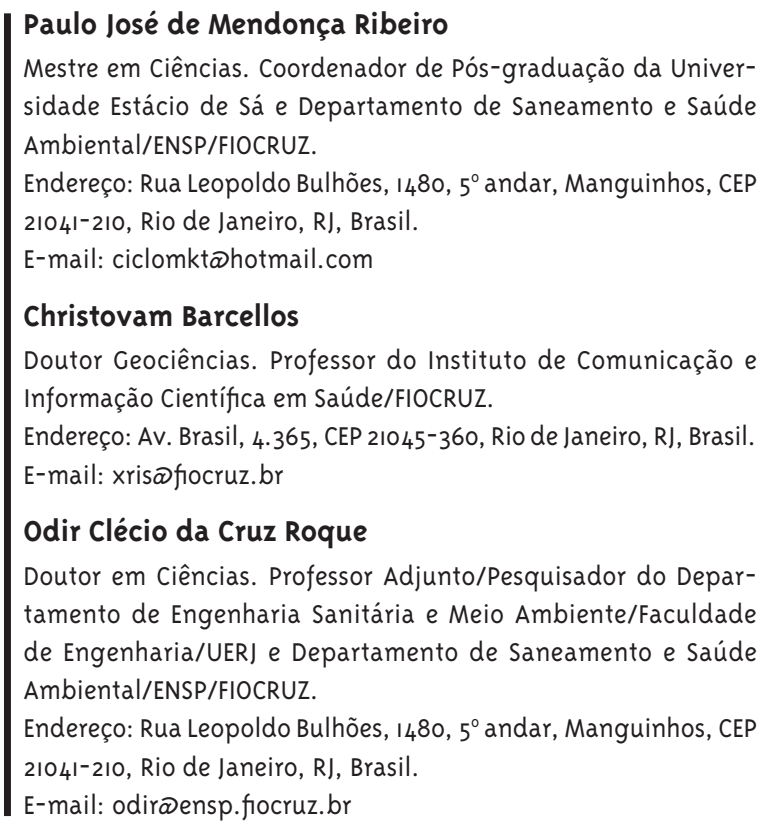

E-mail: odirøensp.fiocruz.br

\section{Resumo}

O objetivo deste trabalho foi identificar e caracterizar um modelo de gestão do marketing como estratégia para promoção do município saudável e sustentável em Miracema (RJ). A estrutura da pesquisa deu-se, primeiro, pela coleta de dados primários, com a realização de entrevistas com gestores municipais para conhecer o Sistema de Gestão Municipal e construir mapas participativos para diagnóstico dos problemas e conflitos. Segundo, uma pesquisa de abordagem qualitativa, interpretando a percepção junto à população por meio de questionário estruturado da problemática no município. Na investigação de ferramentas e instrumentos para resposta à problemática no município de Miracema utilizou-se como referencial a matriz Pressão-Estado-Impacto-Resposta (PEIR). Com base no conhecimento produzido, elaborou-se a proposta de gestão do marketing no município baseada nos indicadores de resposta diagnosticados na esfera municipal. Miracema apresenta potencial para desenvolvimento nos setores primário e secundário. $\mathrm{O}$ agronegócio deve ser desenvolvido no modelo sustentável, em conformidade com políticas públicas capazes de promover a continuidade de investimentos. 0 mesmo aplica-se ao aproveitamento da matéria prima na indústria. Logo, o Zoneamento Econômico Ecológico do município contemplando o ambiente induz a ferramenta indispensável de sua viabilidade.

Palavras-chave: Marketing sustentável; Sustentabilidade socioambiental; Indicadores; Desenvolvimento sustentável; Gestão territorial. 


\section{Abstract}

The objective of this study was to identify and characterize a model of marketing management as a strategy to promote the project of a healthy and sustainable city in Miracema (RJ). The first step was to collect primary data, which was made through interviews conducted with town administrators in order to get acquaintance with the Municipal Management System and build maps for participatory diagnosis of problems and conflicts. Secondly, a qualitative investigation was conducted among the population with the objective of interpreting their perception about the city problems through a structured questionnaire. Having identified the indicators, research tools and instruments to answer to the municipality problems at Miracema, we used the reference matrix Pressure-State-Impact-Response (PEIR in Portuguese). Based on response indicators diagnosed in the sphere of the municipality, the proposal of marketing management was elaborated. Miracema has potential for development in primary and secondary sectors. Agribusiness should be developed in accordance with sustainable public policies that promote continued investment. The same applies to the use of raw material in industry. Therefore, the Ecological Economic Zoning of the municipality contemplating the environment induces the indispensable tool for its viability.

Keywords: Sustainable Marketing; Social and Environmental Sustainability; Indicators; Sustainable Development, Territorial Management.

\section{Introdução}

Conciliar o desenvolvimento econômico e a sustentabilidade socioambiental com garantias está entre os grandes desafios a serem enfrentados pela sociedade moderna. Tendo em vista esta busca pela qualidade de vida sustentável, faz-se necessário que a dimensão ambiental esteja presente nas fases de formulação de objetivos para o gerenciamento estratégico dos níveis nacional, estadual e municipal, havendo, assim, a demanda por instrumentos de gestão que impeçam o agravamento das condições sociais e ambientais como contrapartida ao desenvolvimento (Eroy e Acselrad, 2006).

As dimensões sociais e ambientais passaram a compor os objetivos de gestão das organizações privadas e públicas. A proposta da gestão do marketing sustentável é integrada ao sistema de gestão pública ou empresarial ao ajustar visão interdisciplinar no domínio de instrumental analítico; a perspectiva estratégica ao desenvolvimento de habilidades para tomada de decisões; a ênfase na análise socioambiental à compreensão dos impactos no ambiente interno da organização; alia-se a capacitação e o desenvolvimento de habilidades interpessoais e de liderança (Ministério do Meio Ambiente, 2001). Assim, compatibilizar as necessidades atuais dos municípios nas dimensões: institucional (das políticas públicas e relações de poder), empresarial (geração de emprego e renda), econômica (processo produtivo, estilos de vida, padrões de consumo), social (participação e controle social, redução de iniquidades, processos sociais), criando redes de relações (urbanas, espaciais e sociais) entre ambiente, recursos, qualidade de vida, desenvolvimento e promoção da saúde. Essa abordagem deve integrar as práticas de interdisciplinaridade, intersetorialidade, territorialidade com informação e sustentabilidade socioambiental.

O marketing como estratégia de potencialização do desenvolvimento tem como um de seus objetivos o desenvolvimento econômico socialmente responsável, fundamental para viabilizar projetos que se adaptem às características regionais e à diversidade das necessidades locais, integrando-as à população. Essa estratégia é resultado do reconhecimento dos atores sociais locais e uma divisão equânime de 
custos e benefícios sociais (Mitchell e col., 2010; Almeida, 2007; Calheiros, 2004 apud Silva e col., 2008; Ribeiro, 2009).

O marketing ambiental, social e economicamente responsável de bens e produtos da marca, por empresas que atendam as partes interessadas. No posicionamento de mercado com orientação sustentável, indicará o alto compromisso com a sociedade e o ambiente, mesmo em um cenário altamente competitivo. Portanto, as empresas, públicas ou privadas, com elevado grau de comprometimento e orientação para o mercado sustentável, irão gerar no longo prazo superior desempenho. A inovação social e ambientalmente responsável, na prática, é mais propensa a gerar adicional eficiência operacional e renda. Um compromisso corporativo e institucional com a orientação de mercado sustentável irá refletir uma compreensão da demanda derivada e expectativas da comunidade, que também é passível de fomentar a confiança baseada em trocas, da sociedade, dos governos e das relações das partes interessadas para minimizar o risco de intervenção e regulação (Epstein e Roy, 2003 apud Mitchell, e col., 2010; Almeida, 2007; Brundtland, 1987).

Assim, o desenvolvimento sustentável pressupõe a parceria entre governos e empresas para a reorientação do consumo e produção baseada na ética, transparência e factibilidade. À medida que a humanidade aumenta sua capacidade de intervir na natureza para satisfação de necessidades crescentes, surgem tensões e conflitos quanto ao uso do território e seus recursos. Nos últimos 50 anos, os ecossistemas, e consequentemente os benefícios da biodiversidade como suporte da vida, sofreram mudanças radicais em velocidade e extensão, não comparadas a qualquer geração anterior da humanidade em 200 mil anos (MEA, 2005; Freitas e Porto, 2006; UNEP, 2010).

O Brasil apresenta um processo acelerado de urbanização, com cerca de $84 \%$ dos habitantes vivendo em cidades. As 26 Regiões Metropolitanas (RM) reconhecidas por lei concentram $34 \%$ da população brasileira e $84 \%$ da população urbana (Baeninger, 2010). Em contraste, a população rural brasileira é composta por cerca de 29 milhões de pessoas. Desses, em torno de 525 mil famílias são assentadas pela reforma agrária (IPEA, 2009).
Nesse contexto, carente de políticas públicas, os problemas relacionados aos municípios de pequeno porte são pouco estudados. Houve, nas últimas décadas, uma crescente responsabilização dos municípios pela gestão de diversos setores como a saúde, ambiente e habitação, entre outros. Nas cidades de pequeno porte a situação se tornou dramática devido ao acúmulo de atribuições, que não tem sido acompanhado de um suporte técnico e financeiro para responder às demandas por serviços, e às pressões sociais e políticas locais.

O Brasil possui cerca de 5.037 municípios com menos de 50.00o habitantes, que abrigam cerca de $34 \%$ da sua população total (IBGE, 2012). Eles possuem graves problemas sociais e econômicos, agravados pelos problemas de financiamento. As transferências da União, do Estado e demais participações governamentais alcançaram elevadas proporções nas receitas totais do município, reduzindo a autonomia financeira e a capacidade de arrecadação de receitas locais.

No Rio de Janeiro, a região Noroeste apresenta o pior indicador socioeconômico do Estado, especialmente nas áreas rurais (TCE, 2011). No ano de 2010, Miracema possuía uma população de 26.843 habitantes, 92\% dos quais concentrados na área urbana (IBGE, 2010). A população total tem aumentado em ritmo lento, enquanto decresce em números absolutos e relativos a população rural. 0 empobrecimento em Miracema atinge grande parte da população: 50,19\%, com Índice Gini o,48, que mede a desigualdade de renda, o pior da região Noroeste (PNUD, 2003 apud Rio de janeiro, 2010). A área rural perdeu seu dinamismo devido à crescente descapitalização associada à decadência das "grandes" lavouras comerciais, elevando o processo de esvaziamento do meio rural em razão do declínio de suas agriculturas e promovendo a migração para os centros urbanos, enquanto grandes áreas de terra são abandonadas em degradação (Rio de Janeiro, 2008 apud Souza e col., 2009). A estagnação do setor agropecuário é parcialmente explicada pela baixa produtividade das práticas agrícolas adotadas, caracterizadas pela pequena incorporação tecnológica e susceptibilidade à erosão, comuns em função do elevado gradiente textural e da criação extensiva de gado (Almeida e col., 1988; Tôsto e col., 2003). 
O baixo desempenho dos serviços de saneamento básico é um dos entraves para o desenvolvimento sustentável do município. O percentual de moradores que em 2010 vivia em domicílios com alguma forma de esgotamento sanitário (rede geral ou fossa séptica) era de $87,9 \%$ na zona urbana e $11 \%$ na zona rural, embora a maior parte destes possua abastecimento de água por rede (IBGE, 2010). Os resultados para zona urbana aparentemente demonstram que a situação do esgotamento sanitário da cidade é privilegiada se comparado com a cobertura de esgotos no Brasil urbano, que é de 81\% (Victorino, 2007). Porém, é necessário ressaltar que os dados não separam valores de rede e fossa séptica, pós-encaminhamento dos efluentes das fossas, e que praticamente 100\% dos esgotos são lançados brutos nos corpos hídricos da região (Ottoni, 2008). Por outro lado, os valores para esgotos em zona rural se encontram abaixo dos percentuais brasileiros, de 23,7\% (Victorino, 2007), sendo lançados no meio ambiente sem tratamento.

A consequência sanitária e ambiental da deficiência no saneamento é a contaminação dos corpos hídricos superficiais ou subterrâneos. Essa contaminação é uma das evidências de vinculação entre os problemas nas áreas rurais e aqueles da área urbana. O equacionamento conjunto desses problemas é um desafio que se pretende analisar neste trabalho.

O objetivo geral deste trabalho foi identificar e caracterizar um modelo de gestão do marketing como estratégia para promoção do município saudável e sustentável de Miracema, região Noroeste do Estado do Rio de Janeiro. Para tanto, adotou-se uma abordagem que permitisse o levantamento de problemas dos diversos setores da economia local, buscando bases comuns para a gestão territorial. Foram selecionados e analisados indicadores socioambientais capazes de realizar um diagnóstico preliminar de situação de saúde e condições de vida, bem como promover o debate para o desenvolvimento sustentável entre gestores de diferentes setores da economia local.

O município de Miracema foi escolhido por representar base econômica em serviços, baixo orçamento e com tensões entre setores que comprometem sua vocação e projetos futuros. Além disso, poucas pesquisas com potencial para gerar conhecimento no âmbito do planejamento participativo e da elabo- ração de políticas públicas têm sido realizadas no Noroeste Fluminense.

\section{Metodologia}

A gestão do desenvolvimento sustentável pressupõe a integração de esforços de setores e a ampliação dos horizontes de projetos de desenvolvimento para além do nível local e imediato. Uma das dificuldades encontradas nessa gestão é a carência de instrumentos que permitam essa integração. Neste trabalho adotou-se o modelo Pressão-Estado-Impacto-Resposta (PEIR), desenvolvido pelo Programa das Nações Unidas para o Meio Ambiente (São Paulo, 2004), como estratégia para o reconhecimento dos vínculos entre os problemas ambientais e suas repercussões na saúde. Nesse sentido, foram identificados indicadores e fontes de informação para cada componente da matriz PEIR: o Estado reflete o conjunto de condições ambientais; o Impacto demonstra as consequências dessas condições sobre a saúde e bem-estar; a Pressão revela atividades e processos sociais e políticos causadores; e finalmente a Resposta mostra um conjunto de ideias e ações voltadas para mitigação ou prevenção desses impactos. Como cada componente da matriz refere-se a diferentes setores de governo e níveis de organização social, foram adotados instrumentos específicos para a coleta e análise de dados.

Para retratar o Estado do ambiente foi realizada campanha de amostragem de água nos principais rios do município. Foram analisados parâmetros bacteriológicos e físico-químicos que resultaram no "Relatório da avaliação de qualidade da água" (INEA, 2009) e na pesquisa de campo (visitas técnicas), as quais constam no "Relatório da Inspeção Técnica realizada ao Sistema Ambiental da Cidade de Miracema - RJ" que contém informações sobre a organização do setor ambiental do município e áreas de preservação (Ottoni, 2008).

A avaliação do Impacto foi realizada por meio de entrevistas com moradores do município de Miracema, sendo entrevistadas 18 o pessoas, nos meses de janeiro e julho de 2009. A seleção dos participantes deu-se espontaneamente. Os participantes foram convidados a responder um questionário, e estes convidavam pessoas de seu convívio a participar. 0 
questionário estruturado foi composto por perguntas abertas e fechadas relacionadas a meio ambiente, emprego e renda, educação, saúde e expectativas futuras no município.

Como aproximação ao tema da Pressão foram levantados os diversos pontos de vista dos gestores locais sobre projetos em andamento, problemas sociais e ambientais. Para isso, foram realizadas entrevistas com gestores municipais nas áreas de planejamento e desenvolvimento econômico; meio ambiente e desenvolvimento agropecuário; obras e urbanismo; defesa sanitária animal; assistência social e saúde. Esse levantamento teve dois objetivos: conhecer o sistema de gestão municipal e construir mapas ilustrativos para diagnóstico e gestão territorial. Os principais problemas, para o estudo, divididos nos temas saneamento básico (lixo, esgoto, água e drenagem urbana) e ambiente (erosão, desmatamento, contaminação da água), foram levantados por meio da pesquisa de campo (visitas técnicas) aos locais apontados pelos gestores (Ottoni, 2008).

Relatos, ilustrações, trajetos e roteiros fornecidos pelos entrevistados foram esquematizados para compor elementos do mapeamento. Adotou-se o recurso de gravação digital para as entrevistas, sendo os participantes encorajados a desenhar sobre um mapa-base os principais aspectos relacionados ao desenvolvimento do município: problemas, projetos e potenciais (Goldstein, 2013). Foi cedido a cada entrevistado um mapa da Fundação CIDE (atual CEPERJ) de uso do solo e cobertura vegetal, em tons de cinza em escala 1:25.0oo, que serviu como base para as anotações. Foram cedidas canetas coloridas para que os entrevistados marcassem com cores diferentes os problemas e projetos, compondo cada um sua legenda de cores e a interpretação do território objeto do estudo.

O componente Resposta foi levantado por meio de pesquisa documental em relatórios de diversas instituições (IBGE, IPEA, TCE, BNDES, INEA, CREA, FIOCRUZ, EMBRAPA, PESAGRO-RIO e FIRJAN) ${ }^{1}$ que envolvessem o município de Miracema. Os do- cumentos foram sistematizados segundo as áreas temáticas de economia, ambiente, saúde e sociedade e comparados à visão dos gestores.

\section{Resultados}

Os itens anotados pelos gestores entrevistados foram consolidados em um mapa síntese, obtido pela sobreposição de mapas e destacado em um programa de edição de imagens, conforme Figura 1. As inserções dos gestores, suas declarações e depoimentos, foram representadas por pontos com cores (representadas na Figura 1 por símbolos geométricos em preto e branco) diferentes segundo seus setores econômicos.

Vários problemas, em diferentes áreas do município, foram apontados pelos gestores municipais. Em geral, cada participante mostrou problemas do seu setor específico, com poucas exceções, como a pecuária, que preocupa gestores de diversos setores. Vários entrevistados apontaram as áreas de expansão urbana como um problema, com destaque para o processo de favelização no núcleo urbano, bem como na região Sul do município. Raramente gestores de um setor se referiram a problemas de outro setor, o que demonstra uma visão pouco integrada do território e da pequena importância dada ao ambiente e à gestão ambiental, que ainda não integram as práticas da administração pública. Essa visão setorializada do território se reflete no padrão observado no mapa da Figura 1, com concentração de pontos dos mesmos gestores em áreas determinadas do município e consolidadas em campo conforme o "Relatório da inspeção técnica realizada ao sistema ambiental da cidade de Miracema - RJ" (Ottoni, 2008).

As entrevistas com os miracemenses mostraram uma percepção de quase total negligência dos governantes em questões ambientais. Todos os entrevistados relacionavam saúde e ambiente como determinante para o seu bem-estar. Outra resposta que evidencia a preocupação dos munícipes com o ambiente está no desmatamento, sendo o reflores-

1 IBGE - Instituto Brasileiro de Geografia e Estatística, IPEA - Instituto de Pesquisas Econômicas Aplicadas, TCE - Tribunal de Contas do Estado, BNDES - Banco Nacional de Desenvolvimento Econômico e Social, INEA - Instituto do Estado do Ambiente, CREA - Conselho Regional de Engenharia e Agronomia, FIOCRUZ - Fundação Oswaldo Cruz, EMBRAPA - Empresa Brasileira de Pesquisa Agropecuária, PESAGRO-RIO - Empresa de Pesquisa Agropecuária do Rio de Janeiro e FIRJAN - Fundação das Indústrias de Estado do Rio de Janeiro. 
Figura I - Consolidação de respostas sobre mapa-base a itens setoriais levantados por entrevista com gestores de Miracema (RJ)

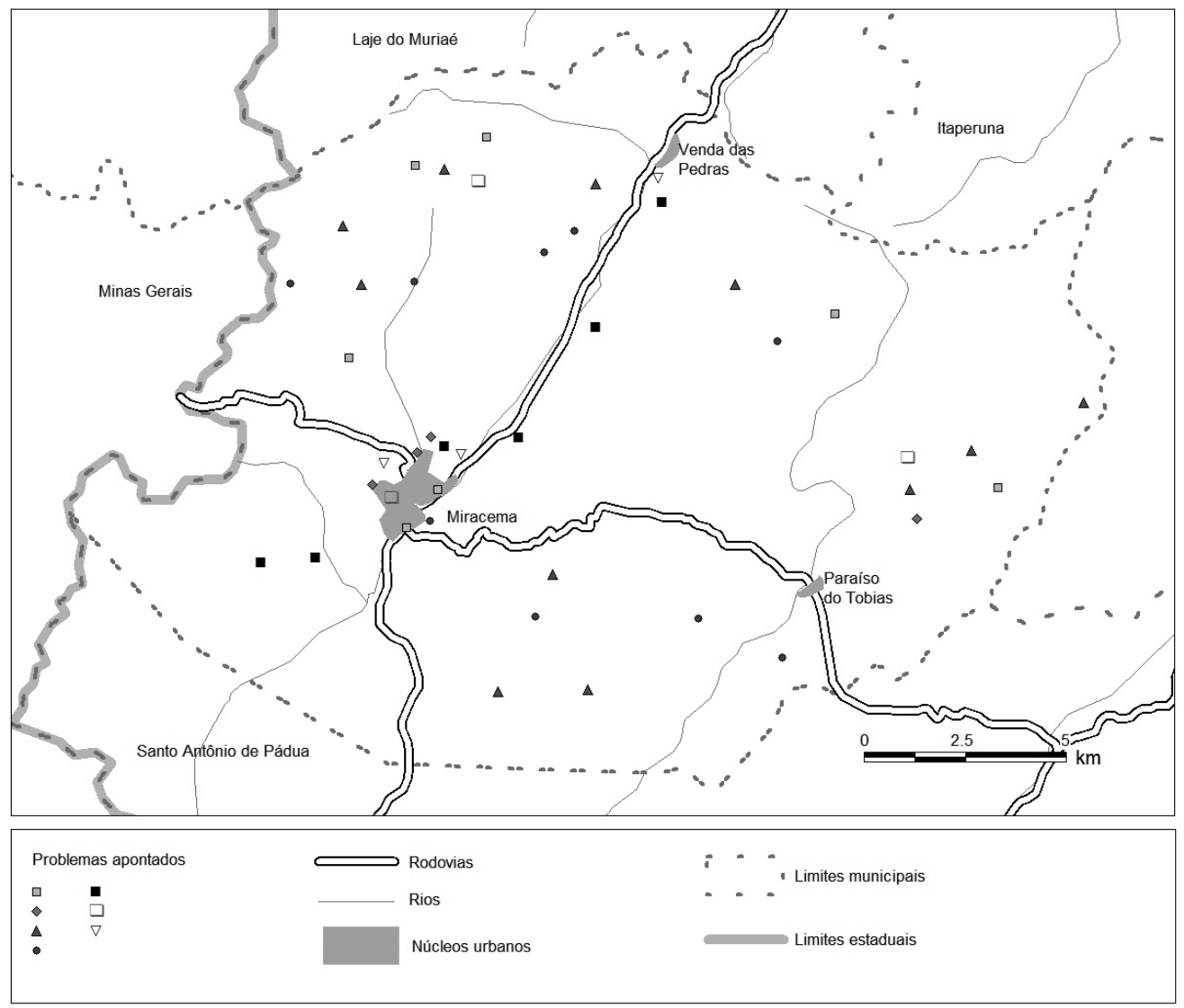

tamento apontado por alguns como política para manutenção ou recuperação da qualidade ambiental do município.

O retrato da ocupação territorial no contexto urbano e rural resulta das transformações impostas ao território pela pressão demográfica e social que caracterizou o município ao longo do século XX. Entre outros aspectos, essa dinâmica reflete um período de crescimento populacional na área urbana - com a precariedade das moradias e o agravamento da pobreza associados - e a expansão da área urbana rumo às áreas periféricas e áreas anteriormente preservadas, onde se localizam os principais mananciais locais. As nascentes do Ribeirão Santo Antônio e Ribeirão do Bonito, que cruzam o município de norte a sul, se localizam em encostas sob pressão das atividades agropecuárias.
Foram apontados potenciais de aproveitamento do turismo de eventos e ecoturismo. Para tanto, segundo os gestores e outros entrevistados, seria importante multiplicar e consolidar destinos turísticos no município, e ao mesmo tempo condicionar o ordenamento do território para obtenção de melhor qualidade estética, funcional e, sobretudo, social da paisagem local.

A problemática que envolve a gestão do município foi analisada com base na matriz PEIR, que auxilia a estruturar informações e identificar relações importantes entre os diversos componentes econômico, social, ambiental, e de saúde desta matriz e assim desenvolver uma visão e compreensão de um dado problema. Os dados secundários levantados neste trabalho mostram um quadro de degradação da qualidade ambiental, principalmente relacionado 
a conflitos com água e uso do solo.

A agropecuária é uma atividade preponderante em área no município, desenvolvida principalmente nas baixadas e encostas, apesar de economicamente pouco expressiva, correspondendo em média a 3,7\% do PIB municipal (TCE, 2011). Os rebanhos de herbívoros se concentram junto às mesmas fontes de água. A manutenção da sanidade dos rebanhos está diretamente relacionada ao conhecimento e monitoramento das enfermidades endêmicas da região, ao seu monitoramento e à avaliação de riscos de transmissão de zoonoses do ambiente silvestre ao doméstico. Pode-se presumir que a vigilância adequada de agravos que acometem os herbívoros alerta para o risco de sua ocorrência na população humana, sendo, portanto, uma estratégia de Saúde Pública.

A informação decorrente do "Projeto de Controle de Zoonoses em Miracema" mostra a incidência de zoonoses no período de 1999 até 2007. Tornou-se crítica em relação à fasciolose, endêmica no município, principalmente na bacia do Ribeirão Santo Antônio e Ribeirão do Bonito, que hoje abrange todo território municipal. Seu controle é altamente complexo; os animais, embora tratados com vermífugos, retornam aos pastos e córregos infectados. E, assim, o mesmo ciclo compreende a cisticercose. Como a predominância em Miracema é o gado leiteiro, a produtividade do rebanho é prejudicada.

Em relação à brucelose e tuberculose animal, destaca-se que nas pequenas propriedades agrícolas do distrito de Paraíso do Tobias, a incidência é baixa. Porém, entre os grandes produtores estabelecidos em todo município a incidência das doenças é maior. Dois grandes fatores de contribuição para incidência e a propagação da brucelose e tuberculose no município são: primeiro, o produtor possui um animal de boa genética e padrão zootécnico bom, mas infectado, o fato omitido no momento da venda; e o segundo, a inspeção dos veterinários habilitado pela Secretaria de Defesa Animal (DAS) do Ministério da Agricultura, Pecuária e Abastecimento (MAPA). Quando da implementação, em 2001, do Programa Nacional de Controle e Erradicação da Brucelose e da Tuberculose Animal (PNCEBT), houve a emissão de muitos laudos falsos, o que reduziu a credibilidade do programa.

No tocante à raiva, há um trabalho para controle da população de morcegos hematófagos no município, em uma parceria entre a Prefeitura, a Empresa de Pesquisa Agropecuária do Estado do Rio de Janeiro (PESAGRO) e a Secretaria de Defesa Animal (DAS/MAPA). Por mio dessa parceria outro grande resultado foi a vacinação contra a febre aftosa.

No período de seca, somado à degradação ambiental no município, há outra preocupação: as infecções por poxvirus. Os reservatórios naturais do vírus são os roedores, que podem infectar os bovinos, sendo mais sensível a vaca leiteira. A infecção se propaga entre os bovinos pelas mãos dos ordenhadores ou, ainda, através dos cálices da ordenhadeira mecânica. Retireiros contraem a infecção durante a ordenha, no contato com as lesões nas tetas das vacas ou com a boca dos bezerros (Romijn e col., 2008; Schatzmayr e col., 2009).

As notificações de agravo pela Secretaria de Saúde ressaltam o papel do matadouro municipal na detecção e controle da doença. É o caso, por exemplo, da tuberculose animal, já que existe probabilidade dos ocupantes da propriedade estarem contaminados. Nesse caso, são encaminhados agentes de saúde para investigação (PESAGRO, 2007).

Em Miracema, parte da zona urbana possui soluções coletivas para esgotamento sanitário, notadamente o centro urbano e as áreas dos bairros e distritos dotados de soluções individuais, como fossas sem manutenção adequada. No âmbito do governo municipal, não existe programa de inspeção e limpeza das mesmas. 0 problema se agrava na zona rural, que tem baixa cobertura de soluções para esgotos.

A consequência sanitária e ambiental da deficiência no saneamento dos esgotos sanitários do município é a contaminação dos corpos hídricos da região, como ilustra o laudo do Instituto Nacional do Estado do Ambiente (INEA) referente a amostras coletadas do Ribeirão Santo Antônio para este estudo, sistematizadas no "Relatório da avaliação de qualidade da água”, divulgado em 2009, que demonstra a presença de poluição hídrica por esgotos sanitários e probabilidade de presença de efluentes industriais nos rios que atravessam o centro urbano e a área rural (INEA, 2009).

Para avaliar o estado do ambiente foi realizada uma única campanha de amostragem de água em 
pontos notáveis do escoamento a montante do centro da cidade, na zona urbana, e a jusante, após passagem por ela. Para um diagnóstico completo sobre a qualidade da água, flutuações e distribuição espacial seria necessária uma campanha sistemática, em diferentes épocas do ano, e abrangendo os diversos cursos de água do município. No entanto, os resultados obtidos permitem verificar a contaminação das águas por coliformes em todos os locais amostrados, a redução dos níveis de oxigênio a jusante da cidade. Por outro lado, os resultados de DBO - Demanda Bioquímica de Oxigênio mostram uma diminuição dos níveis de poluição, o que pode evidenciar uma tendência de recuperação da carga poluidora ao longo do Ribeirão Santo Antônio.

No Noroeste Fluminense a atividade extrativista, desde os séculos XV e XVI, com a exploração do pau-brasil, o ciclo de monocultura da cana-de-açúcar nos séculos XVI e XVII, além da mineração no século XVIII e da produção do café, no XIX, representa o desmatamento progressivo e redução do bioma Mata Atlântica. Foi reduzida a uma taxa de $7 \%$ ao longo do processo de colonização à urbanização no Brasil (Fundação SOS..., 2009). Em Miracema, resistem a pressões 9\% de remanescentes. A Pegada Ecológica (descreve o modo e a forma de viver, na relação direta e de acordo com a capacidade do planeta de oferecer, renovar seus recursos naturais e absorver os resíduos que geramos por séculos) no município é altíssima, comparado a população ao longo do processo citado até os dias de hoje, restavam apenas 2.741 ha em 2009 (Fundação SOS..., 2009) para 2.726 ha em 2011 (Fundação SOS..., 2011), dos 30.442 ha da área original do bioma. Severamente subutilizado e com auxílio de práticas não sustentáveis para uso e manejo de recursos naturais renováveis.

Em Miracema, desde meados do século XVIII até o fim do século XIX, as lavouras de café, milho, arroz e feijão e depois a criação de gado, em 1994, já apresentava área de pastagem em 84\% do território (CIDE, 1994 apud TCE, 2011). Esses são os grandes responsáveis pelo desmatamento do município, e, consequentemente, perda do abastecimento dos lençóis freáticos pelas águas pluviais e as nascentes. A Lei ${ }^{0} 1243$, de 15 de dezembro de 2008, a qual cria o Projeto Produtor de Águas, que autoriza o poder exe- cutivo a prestar apoio financeiro aos proprietários rurais ao implantar ações técnicas e legais para a melhoria da qualidade e quantidade dos mananciais de águas no município de Miracema.

As ausências de cobertura vegetal nos topos de morro não ampliam o Índice de Precipitação Anterior ao adicionar a Zona de Recarga dos lençóis freáticos. Sem preservar as propriedades geomorfológica climática e ambiental (Mares de Morros - Áreas mamelonares tropicais/atlânticas florestadas) estas são susceptíveis aos desastres ambientais e processos erosivos, notadamente intensa erosão laminar em sulcos, constantes voçorocas e movimentos de massa. A erosão causada pelas atividades pastoris deve-se ao número de cabeças de gado por unidade de área. Principalmente no Sul e Sudeste do município a camada de horizonte A do solo foi carreada pelo escoamento superficial, causando o assoreamento das calhas dos cursos d'água e o aumento dos picos de vazão, com consequentes enchentes. Observa-se, ainda, de forma localizada, a redução da disponibilidade de água para abastecimento público, irrigação e dessedentação do rebanho (Carvalho e col., 2000 apud Lumbreras, 2004; Schwenck Jr, 2011).

A degradação ambiental dos rios é agravada pelo produtor rural, que não respeita a legislação no tocante a APP (Área de Proteção Permanente) e RL (Reserva Legal), conforme Lei ${ }^{0} 4 \cdot 771$, de setembro de 1965 e atual redação da Medida Provisória ${ }^{0}$ 2166-67, de 2001.

0 reflorestamento torna-se a especulação econômica de empresas (Eroy e Acselrad, 2006). A possibilidade, anunciada em 2005, da implantação da empresa Aracruz Celulose (com filial também em Itaperuna) e da cultura do eucalipto no município despertou a resistência de pecuaristas e produtores rurais, antevendo uma difícil convivência diante do volume de água a ser requerido pela nova atividade. O poder público foi convocado a embargar atividades ou simplesmente arbitrar decisões (Oliveira Jr e Dias, 2005). Apoiadas pela Lei Estadual 4063, de 02 de janeiro de 2003 (Rio de Janeiro, 2007b), conforme princípios e objetivos estabelecidos no Decreto 4297, de 10 de julho de 2002, que cria o Zoneamento Ecológico Econômico do Brasil, investem na expansão das florestas plantadas de eucalipto (Brasil, 2002). 
Apesar da forte mobilização de diversos movimentos sociais aglutinados, ONG e ambientalistas com expressivas vitórias no conflito com a Aracruz Celulose no Espírito Santo (matriz), a Lei 4063 é revogada pela Lei 5.067, de o9 de julho de 2007 (Rio de Janeiro, 2007a), a qual, segundo Silva (2010), "traz alterações e facilidades para a silvicultura comercial, com o ônus total para o estado na realização do ZEE-RJ”, ausência de EIA-RIMA nas áreas com plantio de eucalipto em até 400 hectares nas regiões hidrográficas do Baixo Paraíba (IX) e Itabapoana (X) e a diminuição no percentual (de 30\% para 20\%) da área a ser plantada com espécies nativas. Em vigor desde sua aprovação, apesar da Ação Direta de Inconstitucionalidade 4069 (Brasil, 2008), protocolada em 16 de abril de 2008, até 2009 a Deliberação CECA $n^{0} 4.543$, de 11 de janeiro de 2005, licenciava a silvicultura e o plantio exótico no Estado do Rio de Janeiro (Rio de janeiro, 2005) sem o amparo de Decreto $n^{0} 41.968$, que apenas em 29 de julho 2009 é regulamentado (Rio de Janeiro, 2009a).

Através do fomento florestal, isto é, um projeto no qual são firmados contratos de fornecimento entre o produtor e a empresa, as mudas, o adubo, os agroquímicos e a assistência técnica para desenvolver as plantações são fornecidos. Sendo um assalariamento disfarçado, esse contrato representa na verdade uma forma de monopolização, pois o agricultor tem apenas uma opção de comprador (Alentejano e Gonçalves apud Silva, 2010).

A estrutura fundiária descreve-se por densidade rural baixa, menos de $10 \mathrm{hab} / \mathrm{km}^{2}$. Relevo de colinas dissecadas e planícies fluviais, com solos profundos e bem drenados, porém "estressados" por índices baixos de evapotranspiração causados pelo intenso desmatamento das bacias. Cerca de $80 \%$ da área do município são ocupados por estabelecimentos agropecuários. Pouco mais de $74 \%$ deles têm menos de 50 hectares; com média a baixa diversificação produtiva, associa-se ao processo de concentração de terras.

As atividades agrícolas são limitadas em função do relevo movimentado e da deficiência hídrica prolongada. Destacam-se as culturas de arroz, milho e tomate, registrando-se também a presença de cana- -de-açúcar. A produtividade das culturas no geral é baixa. 0 mesmo se pode afirmar com relação à pecuária, com predomínio de pastagens subaproveitadas, dado que a produtividade do rebanho bovino na região é menor que a média estadual.

O agravamento da realidade agrossocioeconômica e cultural dessa região indicam que a adoção de sistemas de manejo inadequados - as utilizações de áreas impróprias para atividades agrícolas, associadas à eliminação de matas ciliares - constituem-se na principal causa do atual cenário de degradação das terras e empobrecimento dos agricultores, e mais, a partir da CLT - Consolidação das Leis Trabalhistas, pelo Decreto-Lei $n^{0}$ 5.452, de 1 de maio de 1943, sancionada pelo então presidente Getúlio Vargas, unifica todas as leis do trabalho existente no Brasil. A lei, estabelece direitos iguais aos trabalhadores rurais e urbanos.Com isso os proprietários rurais adotam medidas extremas junto aos "trabalhadores", já que seus custos indenizatórios deveriam retroagir desde o início da atividade de seu empregado. Consequentemente, sem atividade na região rural, migram para a zona urbana ocupando as áreas vulneráveis e proporciona condições de baixos índices de desenvolvimento e de indigências (Lumbreras, 2004), residências irregulares e loteamentos ilegais, bem como o avanço da favelização.

Embora alguns projetos habitacionais em $1983 \mathrm{e}$ 1984 tenham sido iniciados com financiamento do Governo Federal restou a regularização fundiária, o que agravou as ocupações irregulares nas áreas urbanas.

Segundo a Secretaria de Assistência Social, em 2008, com IDH-M o,733 e Índice GINI negativo o,6o comparado a Região Nordeste, Miracema tem 70\% da população dependente da Assistência Social. No Programa Bolsa Família, Miracema em junho de 2010 apresentava 1920 famílias beneficiárias. Porém, com um total de 3542 famílias cadastradas sendo 3372 destas, com renda mensal de R\$ 232,50 (1/2 salário mínimo em 2008). Atendidas pelos CRAS - Centro de Referência da Assistência Social, distribuídos nas regiões onde concentram as famílias na faixa de pobreza provendo acompanhamento integral do recém nascido ao idoso. 


\section{Discussão}

A matriz de indicadores PEIR foi sintetizada na figura 2, que mostra fatores levantados para os níveis de Pressão, Estado, Impacto e Resposta para o caso do município de Miracema (RJ).

Os problemas e recursos locais foram sintetizados em um croqui que mostra áreas de expansão e de tensão entre setores economicos locais (figura 3).

Alguns conflitos de gestão territorial podem ser depreendidos no croqui, que mostra a proximidade de padrões incompatíveis de uso e ocupação do solo em Miracema, e sua relação com as desigualdades e crescimento urbano. Os remanescentes de Mata Atlântica são apontados ao mesmo tempo como recurso para preservação de espaços turísticos (turismo ecológico e turismo rural), e como impedimento para o desenvolvimento da agricultura. Estas florestas também seriam a garantia de água em quantidade e qualidade para abastecimento da cidade. A expansão da cidade em direção a campos agricultáveis foi mencionada por diversos gestores entrevistados, com principal ênfase no processo de favelização da periferia da cidade.

\section{Figura 2 - Diagrama da matriz PEIR para o caso do município de Miracema (RJ)}

\section{Pressão}

Crescimento e densidade populacional

Desigualdades de renda (GINI)

Índice de Desenvolvimento Humano Municipal

Expansão da área urbana

Redução da cobertura vegetal

Consumo de água

Destinação de águas residuais e pluviais

Produção de resíduos sólidos

Uso de agroquímicos

\section{Estado}

Qualidade das águas superficiais e subterrâneas Qualidade da água de abastecimento

Escassez de água

Área de erosão e assoreamento

Arborização urbana

Diversidade de espécies silvestres

Unidades de Conservação e áreas correlatas

Acessibilidade a área de lazer

Fauna sinantrópica e animais domésticos

\section{Impacto}

Doenças de veiculação hídrica Incidência de zoonoses

Ocorrência de inundações e escorregamentos Alterações microclimáticas

Despesas com saúde devido a doenças

Perda de biodiversidade

\section{Resposta}

Plano Diretor Municipal

Legislação de proteção a mananciais

Agenda 2I Local

Educação Ambiental

Organizações Não-governamentais Ambientalistas

Tributação ambiental

Controle de vetores, fauna sinantrópica e animais soltos

Ligações domiciliares de água e esgoto

Recuperação de áreas de inundação e escorregamento

Áreas de erosão e assoreamento recuperadas

Reabilitação de áreas degradadas

Investimento em água e esgoto

Investimento em Gestão de Resíduos Sólidos

Recuperação de resíduos recicláveis

Ampliação da cobertura vegetal

Criação e gestão de Unidades de Conservação

Reabilitação e soltura de animais silvestres 


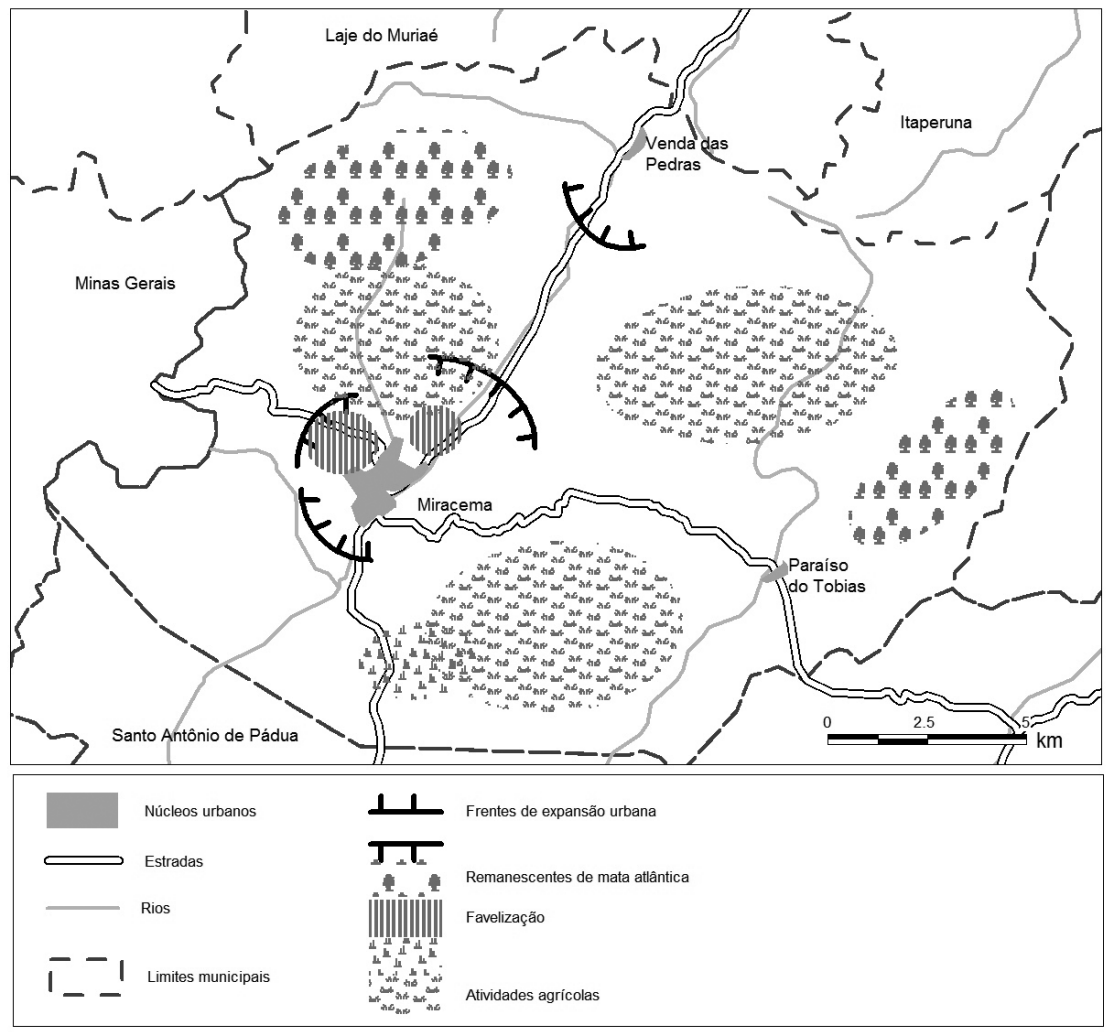

Conflitos em áreas de expansão em direção as áreas de preservação (dentro das áreas rurais) não respeitando a legislação. A quase totalidade de formações florestais remanescentes, concentradas em áreas privadas, está submetida às pressões de ocupação exploração. Além do desmatamento, que promove a destruição e perda de habitat, a fragmentação causa o isolamento e a consequente redução das espécies; desmatamento de encostas, matas ciliares, topos de morro e extinção de nascentes.

A erosão decorrente do desmatamento de Mata Atlântica está associada a uma agricultura predatória e pecuária extensiva, que contribuem para a pauperização regional e para o êxodo rural. Alguns projetos em curso, voltados para a preservação de florestas em pontos críticos como margens de rios, nascentes, encostas e topo de morros, permitem a retomada da vocação de turística e uma agricultura ecologicamente sustentável. O zoneamento ecológico-econômico do município permite direcionar a agricultura e pecuária diversificadas, visando à produção de alimentos para o mercado regional. A recente criação da Unidade de Conservação APA Miracema e o REVIS da Ventania conforme resultado do estudo em questão (Ribeiro, 2009) validada e inserida no CNUC- Cadastro Nacional de Unidades de Conservação da Natureza do Ministério do Meio Ambiente, através do Decreto, 0261, de 15/12/2010 de Miracema (Miracema, 2010). Pode atuar como exemplo para o fomento ao Turismo Sustentável.

Finalmente, há dificuldade e capacidade do regime para abranger a dinâmica multidimensional e multi-nível nas relações de problemas econômicos, ambientais, sociais e sanitários. A maioria dos problemas são caracterizados pela insustentabilidade, devido à complexidade no espaço e tempo dos problemas, exacerbados por várias pressões naturais e antropogênicas capazes de causar impactos.

As pressões, por sua vez, representam as consequências das forças motrizes, que podem ser positivas ou negativas A maioria das fontes literárias considera apenas fatores antropogênicos como 
forças motrizes (Maxim e col., 2009; Giupponi, 2007; Rogers e Greenaway, 2005). "Empreendidas em diferentes esferas e áreas de governo e, ainda, executadas por iniciativas de Organizações Não Governamentais, essas ações configuram hoje um conjunto variado de respostas aos problemas ambientais das cidades" (Hacon, 2008). Por definição, uma pressão é o resultado de aplicação de força sobre o território e sua população quando a abordagem é socioambiental (Hacon, 2008). Os elementos que caracterizam a pressão sobre o ambiente se relacionam às atividades humanas e sua dinâmica, ou seja, as causas dos problemas ambientais (PNUMA, 2004). A intensidade e consequentemente a exaustão, decorrentes das pressões antrópicas sobre o ambiente, expressam-se em mudanças na qualidade e os serviços dos ecossistemas. 0 estado do ambiente, em Miracema e no Noroeste Fluminense, e os impactos socioambientais decorrentes impõem à sociedade o "empenho na formulação e implementação de políticas, planos, programas e projetos voltados à melhoria da qualidade ambiental nos municípios. Contribui deste modo, a capacidade de recuperação da estrutura, função e organização do ecossistema afetado decorre o Impacto Ambiental. No nível local, o impacto ambiental compromete a qualidade de vida da população (Hacon, 2008), em razão dos efeitos diversos e negativos que afetam a saúde dos habitantes e influenciam o cotidiano da cidade associado a vulnerabilidade urbana e impactos nas finanças públicas e privadas.

\section{Conclusão}

Para o desenvolvimento sustentável tornar-se viável, a gestão pública deve ser democratizada e descentralizada; construir a sinergia local, municipal e microrregiões. A participação dos atores sociais inclui o Sistema de Gestão. Isto é, no planejamento que possibilite atuar numa perspectiva de longo prazo as perspectivas sociais e implementem a capacitação de elevar as oportunidades sociais, econômicas, cultural e as condições de vida digna a população.

Miracema apresenta potencial para desenvolvimento nos setores primário e secundário. O agronegócio deve ser desenvolvido no modelo sustentável em conformidade a políticas públicas capazes de promover a continuidade de investimentos federais.
O mesmo aplica-se ao aproveitamento da matéria prima na indústria. Logo, o Zoneamento Econômico Ecológico do município contemplando o ambiente, induz a ferramenta indispensável de sua viabilidade.

O diferencial do município, ainda que atualmente incipiente, é o turismo ecológico e rural. 0 primeiro fator básico está em sua gente simples e amigável que certamente contribuiria sobremaneira para fomentar o potencial nesta atividade, na geração de emprego e renda. O benefício reduziria os conflitos entre a zona rural e urbana, pois requer investimentos em saneamento nos distritos ao ampliar suas infraestruturas.

Ao promover a organização social e o avanço da participação popular, deve, antes de tudo, priorizar a qualificação dos grupos sociais para que se apropriem dos instrumentos de gestão ambiental pública, capacitando-os para uma atuação cidadã em prol da melhoria da qualidade socioambiental dos municípios, do estado e do nosso país. Nesta perspectiva torna-se estratégico o controle social da gestão ambiental pública.

Essa proposta possibilitou adequar a informação "intra" e "entre" as secretarias e sugere uma Coordenação de Marketing. Com eixo estratégico a nível hierárquico de secretaria com o objetivo inicial de gerenciar a comunicação e informação na inserção da gestão socioambiental com vistas a promoção do município saudável e sustentável. As ações partem para o que convencionou-se denominar Processos de Participação - oficinas com a sociedade; oficinas temáticas; entrevistas e reuniões; sensibilização. Além disso, são necessários estudos técnicos territoriais, para construção de cenários prospectivos definindo estratégias que propiciem instrumentos legais com base na viabilidade financeira, projetos estratégicos e territoriais à um Sistema da Gestão Socioambiental com viabilidade política.

Os instrumentos utilizados neste estudo atenderam ao objetivo de levantamento das questões socioambientais no município. Sugere-se um modelo de gestão do marketing baseado na sustentabilidade socioambiental. Porém, isto requer um aprofundamento que demanda o acesso a informações mais detalhadas. A oferta de informações permitiria levantar e planejar projetos de desenvolvimento considerando as especificidades de Miracema e do noroeste fluminense. A transparência permite o entendimento das 
qualidades e entraves que atuam sobre a situação socioambiental dos municípios fluminenses, e a população deve ser vista como parceira no enfrentamento de problemas na Administração Pública.

\section{Homenagem}

Procuramos homenagear com este trabalho o professor Odir Clécio da Cruz Roque, que faleceu em 14 julho de 2013. Odir era engenheiro químico, professor e pesquisador, desde 1973, da área de engenharia sanitária e ambiental em cursos de pós-graduação da ENSP-Fiocruz e de graduação e pós da Faculdade de Engenharia da Universidade do Estado do Rio de Janeiro (UERJ. Em pesquisa, desenvolveu processos de tratamento de esgotos e conquistou a primeira patente internacional da Fiocruz em engenharia sanitária. Foi diretor da ENSP de janeiro a julho de 2001 e chefe do Departamento de Saneamento e Saúde Ambiental (DSSA) da Escola. Durante sua trajetória profissional, buscou processos e projetos de baixo custo em tratamento de esgotos, redes e operação, colaborando para a melhoria da qualidade de vida da população de vários municípios por meio da ampliação da cobertura de saneamento básico e ambiental, com reflexos positivos na saúde pública. Recebeu vários prêmios ao longo de sua brilhante trajetória. O último: Prêmio Oscar Niemeyer de Trabalhos Científicos e Tecnológicos no início deste ano, instituído pelo Conselho Regional de Engenharia e Agronomia do Rio de Janeiro (CREA-RJ). Em 2010, com o Prêmio CREA-RJ de Meio Ambiente, que ele considerava muito relevante, pois é a mais valiosa distinção do Conselho nessa área. Graduou-se em engenharia química na UFRRJ, em 1969, obteve especialização em Engenharia em Saúde Pública, em 1971, pela Fiocruz, e, em 1997, recebeu o título de doutor em Saúde Pública pela ENSP/Fiocruz. Seu temperamento amável, caráter e espírito conciliador cativaram todos os que tiveram o privilégio de trabalhar, aprender e conviver com Odir. Somos gratos.

\section{Referências}

ALMEIDA, D. L. et al. Manual de adubação para o

Estado do Rio de Janeiro. n. 2. Itaguaí, RJ: Editora Universidade Rural, 1988. 178 p.
ALMEIDA, F. Os desafios da sustentabilidade. Rio de Janeiro: Elsevier, 2007.

ANDREWS, R. N. L. Environmental regulation and business "self-regulation". Policy Sciences, Nova York, v. 31, n. 3, p. 177-197, 1998.

BAENINGER, R. População e cidades: subsídios para o planejamento e para as políticas sociais. Campinas: Núcleo de Estudos de População Nepo/Unicamp; Brasília: UNFPA, 2010.

BRASIL. Decreto-lei ${ }^{0} 4.297$, de 10 de julho de 2002. Regulamenta o art. 9, inciso II, da Lei no 6.938 , de 31 de agosto de 1981, estabelecendo critérios para o zoneamento ecológico-econômico do Brasil - ZEE, e dá outras providências. Diário Oficial da União, 11 jul. 2002. Seção 1, p. 6. Disponível em: <http://www.bvsde.paho.org/ bvsacd/cd38/Brasil/D4297-02.pdf.htm>. Acesso em: 12 jul. 2009.

BRASIL. Supremo Tribunal Federal. Ação Direta de Inconstitucionalidade $\mathrm{n}^{0}$ 4069, de 17 abr. 2008. Medida cautelar em Ação Direta de Inconstitucionalidade 4.069-3 Rio de Janeiro. Brasília, DF, 2008. Disponível em: <http:// redir.stf.jus.br/paginadorpub/paginador. jsp?docTP=TP\&docID=349588>. Acesso em: o4 out. 2011.

BRUNDTLAND, G. H. (Ed.). Our common future: The World Commission on Environment and Development. Oxford: Oxford University Press, 1987.

EROY, J. P.; ACSELRAD, H. (Coords.). Mapa dos conflitos ambientais no Estado do Rio de Janeiro (CD-ROM). Rio de Janeiro: FASE/BSD \& ETTERN/IPPUR/UFRJ, 2006.

FREITAS, C. M.; PORTO, M. F. Saúde, ambiente e sustentabilidade. Rio de Janeiro: Editora Fiocruz, 2006.

FUNDAÇÃO SOS MATA ATLÂNTICA. Instituto Nacional de Pesquisas Espaciais. Atlas dos remanescentes florestais da Mata Atlântica: período 2005-2008. São Paulo, 2009. Disponível em: <http://mapas.sosma.org.br/site_media/ download/atlas\%2omata\%2oatlanticarelatorio2005-2008.pdf>. Acesso em: 23 maio 2010. 
FUNDAÇÃO SOS MATA ATLÂNTICA. Instituto

Nacional de Pesquisas Espaciais. 2011. Atlas dos remanescentes florestais da Mata Atlântica: período 2008-2010. São Paulo, 2011. Disponível em: <http://mapas.sosma.org.br/site_media/ download/atlas_2008-10_relatorio\%2ofinal_ versa02_julho2011.pdf >. Acesso em: 03 ago. 2011.

GIUPPONI, C. Decision support systems for implementing the European Water Framework Directive: The MULINO Approach. Environmental Modelling and Software, Canberra, p. 248-258, 2007.

GOLDSTEIN, A. R. et al. A experiência de mapeamento participativo para a construção de uma alternativa cartográfica para a ESF. Ciência \& Saúde Coletiva, Rio de Janeiro, v. 18, n. 1, p. 45-56, 2013.

HACON, S. (Coord.). Geo saúde: cidade de São Paulo. Rio de Janeiro: ENSP/FIOCRUZ, 2008.

IBGE - Instituto Brasileiro de Geografia e Estatística. Sistema IBGE de Recuperação Automática - SIDRA. IBGE, 2010. Rio de Janeiro, 2010. Disponível em: <http://www.sidra.ibge.gov. $\mathrm{br} / \mathrm{bda} /$ tabela/listabl.asp?c=1612\&z=p\&0=24>. Acesso em: 18 set. 2011.

IBGE - Instituto Brasileiro de Geografia e Estatística. Estimativas populacionais para os municípios brasileiros em 01.07.2012. Rio de Janeiro, 2012. Disponível em: <http://www.ibge.gov. br/home/estatistica/populacao/estimativa2012/ default.shtm>. Acesso em: 20 jun. 2012.

INEA - Instituto Estadual do Ambiente. Relatório da avaliação de qualidade da água. Rio de Janeiro, 2009.

IPEA - Instituto de Pesquisa Econômica Aplicada. Brasil em desenvolvimento: Estado, planejamento e políticas públicas. Brasília, DF: IPEA, 2009.

LUMBRERAS, J. F. et al. Macropedoambientes da Região Noroeste Fluminense: uma contribuição ao planejamento ambiental. Rio de Janeiro: Embrapa Solos, 2004. Documentos, 64 .

MAXIM, L.; SPANGENBERG, J. H.; O`CONNOR, $\mathrm{M}$. An analysis of risks for biodiversityunder the DPSIR framework. Ecological Economics, Nova York, v. 69, n. 1, p. 12-23, 2009.
MEA - MILLENNIUM ECOSYSTEM ASSESSMENT. Relatório Síntese da Avaliação Ecossistêmica do Milênio, 2005. Washington, DC, 005. Disponível em: <http://www.millenniumassessment.org/en/ About.aspx>. Acesso em: 25 jun. 2013.

MINISTÉRIO DO MEIO AMBIENTE. $A_{3} P$ - Agenda ambiental na administração pública. Brasília, DF, 2001.

MIRACEMA (município). Decreto Municipal n. o 261, de 15 de dezembro de 2010. Sobre a criação da área de proteção ambiental Miracema (APA Miracema) e do refúgio de vida silvestre da ventania (REVIS da Ventania). Miracema, 2010.

MITCHELL, R. W.; WOOLISCROFT, B.; HIGHAM, J. Sustainable market orientation: a new approach to managing marketing strategy. Journal of Macromarketing, California, v. 30, n. 2, p. 160-170, 2010.

OLIVEIRA JUNIOR, J. C.; DIAS, H. C. T.

Precipitação efetiva em fragmento secundário da Mata Atlântica. Revista Árvore, Viçosa, v. 29, n. 1, p. 9-15, 2005 .

OTTONI, A. B. Relatório da inspeção técnica realizada ao Sistema Ambiental da Cidade de Miracema. Rio de Janeiro: Conselho Regional de Engenharia, Arquitetura e Agronomia, 2008.

PESAGRO - Empresa de Pesquisa Agropecuária do Estado do Rio De Janeiro. Controle das principais zoonoses e febre aftosa no rebanho bovino do município de Miracema: relatório. Rio de Janeiro: PESAGRO, 2007.

PNUMA - Programa das Nações Unidas para o Meio Ambiente. Metodologia para a elaboração de Relatórios GEO Cidades. Cidade do México: PNUMA, 2004.

RIBEIRO, P. J. M. Uma proposta de gestão do marketing no município de Miracema/RJ como estratégia para promoção do município saudável e sustentável. 2009. Dissertação (Mestrado em Ciências) - Fundação Oswaldo Cruz, Escola Nacional de Saúde Pública Sérgio Arouca, Rio de Janeiro. 
RIO DE JANEIRO (Estado). Comissão Estadual de Controle Ambiental. Deliberação ${ }^{0}{ }^{4} 4543$, de 11 de janeiro de 2005. Dispõe sobre Licenciamento de Projetos de Silvicultura. Diário Oficial do Estado do Rio de Janeiro, Rio de Janeiro, 12 jan. 2005.

RIO DE JANEIRO. (Estado). Decreto $n^{\circ} 41.968$ de 29 de julho de 2009. Regulamenta a lei ${ }^{\circ}$ 5.067 , de o9 de julho de 2007 , no que se refere a empreendimentos de silvicultura econômica, definidos como pequena e média escala, no Estado do Rio de Janeiro. Diário Oficial do Estado do Rio de Janeiro, Rio de Janeiro, 30 jul. 2009. n. 136, p.1-3.

RIO DE JANEIRO (Estado). Secretaria de Estado de Planejamento e Gestão. Plano de desenvolvimento sustentável do norte e noroeste do estado do Rio de Janeiro. v. 3. Rio de Janeiro: SEPLAG, 2010.

RIO DE JANEIRO (Estado). Lei n. 5.067, de o9 de julho de 2007. Dispõe sobre o zoneamento Ecológico-Econômico do Estado do Rio de Janeiro e definindo critérios para a implantação da atividade de silvicultura econômica no Estado do Rio de Janeiro. Rio de Janeiro, 2007a. Disponível em: <http://alerjln1.alerj.rj.gov.br/contlei.nsf/e958 9b9aabdgcac8032564feoo65abb4/odbce6678eae 16c483257315006c33od?OpenDocument>. Acesso em: 21 dez. 2008.

RIO DE JANEIRO. Lei n. 4.063 de o2 de janeiro de 2003. Determina a realização do Zoneamento Ecológico-Econômico do Estado do Rio de Janeiro. [s.l.], 2007b. Disponível em: <http://alerjlnı.alerj. rj.gov.br/scproo711.nsf/6b8b30130497e5do83256 6ecoo18d81f/20a69469564fee10832572dooo664 8ob?OpenDocument>. Acesso em: 22 mar. 2008.

ROGERS, S. I.; GREENAWAY, B. A UK perspective on the development of marine ecosystem indicators. Marine Pollution Bulletin, Hamburg, v. 5o, n. 1, p. 9-19, 2005.

ROMIJN, P. C. et al. Ações em saúde na vigilância e prevenção de enfermidades infecciosas no município de Miracema, RJ. Revista Brasileira de Medicina Veterinária, Rio de Janeiro, 2008.

SÃO PAULO. (município). Secretaria Municipal do Verde e do Meio Ambiente. GEO Cidade de São Paulo: panorama do meio ambiente urbano. São Paulo: SVMA, IPT, PNUMA, 2004.
SCHATZMAYR, H. G. et al. Infecções humanas causadas por poxvirus relacionados ao vírus vaccinia no Brasil. Revista Brasileira de Medicina Tropical, São Paulo, v. 42, n. 6, p. 672-676, 2009.

SCHWENCK JR, P. Relatório de avaliação ambiental RioRural. Rio de Janeiro:

Banco Internacional para Reconstrução e Desenvolvimento, 2011.

SILVA, M. P. S.; BARBOSA, T. R. L.; BARROSO, D. G. Preservação de nascentes. Niterói: Programa Rio Rural, 2008. (Manual técnico, 8).

SILVA, T. L. A. A territorialização da monocultura do eucalipto (e da Votorantim) no médio Vale do Paraíba Fluminense. In: ENCONTRO DA REDE DE ESTUDOS RURAIS. Mundo Rural, Políticas Públicas, Instituições e Atores em Reconhecimento Político, 4., Curitiba, 2010. Anais... Curitiba: Universidade Federal do Paraná, 2010.

SOUZA, P. M. de, et al. Padrão de desenvolvimento tecnológico dos municípios das Regiões Norte e Noroeste do Rio de Janeiro. Revista de Economia e Sociologia Rural, Brasília, v. 47, n. 4, p. 946-969, 2009.

TÔSTO, S. G. et al. Diagnóstico socioeconômico dos municípios da região noroeste do Estado do Rio de Janeiro. Rio de Janeiro: Embrapa Solos, 2003. (Boletim de pesquisa e desenvolvimento, 41).

TCE - Tribunal de Contas do Estado do Rio De Janeiro. Estudo socioeconômico 2001-2011, Miracema. Rio de Janeiro: TCE, 2011.

UNEP - United Nations Environment Programme. Year Book 2010. New York: UNEP, 2010.

VICTORINO, C. J. A. Planeta água morrendo de sede: uma visão analítica na metodologia do uso e abuso dos recursos hídricos. Porto Alegre: EDIPUCRS, 2007.

Recebido em: 04/10/2011

Reapresentado em: 20/10/2012

Aprovado em: 29/10/2012 